\title{
Time-lapse three-dimensional imaging of crack propagation in beetle cuticle
}

DOI:

10.1016/j.actbio.2019.01.031

\section{Document Version}

Accepted author manuscript

Link to publication record in Manchester Research Explorer

\section{Citation for published version (APA):}

Sykes, D., Hartwell, R., Bradley, R. S., Burnett, T. L., Hornberger, B., Garwood, R. J., \& Withers, P. J. (2019). Time-lapse three-dimensional imaging of crack propagation in beetle cuticle. Acta Biomaterialia, 86, 109-116. https://doi.org/10.1016/j.actbio.2019.01.031

\section{Published in:}

Acta Biomaterialia

\section{Citing this paper}

Please note that where the full-text provided on Manchester Research Explorer is the Author Accepted Manuscript or Proof version this may differ from the final Published version. If citing, it is advised that you check and use the publisher's definitive version.

\section{General rights}

Copyright and moral rights for the publications made accessible in the Research Explorer are retained by the authors and/or other copyright owners and it is a condition of accessing publications that users recognise and abide by the legal requirements associated with these rights.

\section{Takedown policy}

If you believe that this document breaches copyright please refer to the University of Manchester's Takedown Procedures [http://man.ac.uk/04Y6Bo] or contact uml.scholarlycommunications@manchester.ac.uk providing relevant details, so we can investigate your claim.

\section{OPEN ACCESS}




\section{Accepted Manuscript}

Full length article

Time-lapse three-dimensional imaging of crack propagation in beetle cuticle

Dan Sykes, Rebecca Hartwell, Rob S. Bradley, Timothy L. Burnett, Benjamin Hornberger, Russell J. Garwood, Philip J. Withers

PII:

S1742-7061(19)30051-0

DOI: https://doi.org/10.1016/j.actbio.2019.01.031

Reference: ACTBIO 5887

To appear in: $\quad$ Acta Biomaterialia

Received Date: $\quad 6$ September 2018

Revised Date: 9 January 2019

Accepted Date: $\quad 14$ January 2019

Please cite this article as: Sykes, D., Hartwell, R., Bradley, R.S., Burnett, T.L., Hornberger, B., Garwood, R.J., Withers, P.J., Time-lapse three-dimensional imaging of crack propagation in beetle cuticle, Acta Biomaterialia (2019), doi: https://doi.org/10.1016/j.actbio.2019.01.031

This is a PDF file of an unedited manuscript that has been accepted for publication. As a service to our customers we are providing this early version of the manuscript. The manuscript will undergo copyediting, typesetting, and review of the resulting proof before it is published in its final form. Please note that during the production process errors may be discovered which could affect the content, and all legal disclaimers that apply to the journal pertain. 
Time-lapse three-dimensional imaging of crack propagation in beetle cuticle

Dan Sykes ${ }^{1 *}$, Rebecca Hartwell ${ }^{1 \#}$, Rob S. Bradley ${ }^{1 \# \#}$, Timothy L. Burnett ${ }^{1}$, Benjamin Hornberger ${ }^{2}$, Russell J. Garwood $^{3,4}$ and Philip J. Withers ${ }^{1}$

${ }^{1}$ Henry Moseley X-ray Imaging Facility, The Royce Institute, School of Materials, The University of Manchester, Manchester, M13 9PL, UK.

${ }^{2}$ Carl Zeiss X-ray Microscopy Inc., Pleasanton, CA, USA.

${ }^{3}$ School of Earth and Environmental Science, The University of Manchester, Manchester, M13 9PL, UK.

${ }^{4}$ Earth Sciences Department, Natural History Museum, London, SW7 5BD, UK

\#Current address: Glass and Facade Technology Research Group, Department of Engineering, University of Cambridge, Trumpington Street, Cambridge, CB2 1PZ, UK.

\#\#Current address: Geotek Ltd, Daventry, NN11 8PB, UK.

*Corresponding author

\section{Abstract}

Arthropod cuticle has extraordinary properties. It is very stiff and tough whilst being lightweight, yet it is made of rather ordinary constituents. This desirable combination of properties results from a hierarchical structure, but we currently have a poor understanding of how this impedes damage propagation. Here we use non-destructive, time-lapse in situ tensile testing within an X-ray nanotomography (nCT) system to visualise crack progression through dry beetle elytron (wing case) cuticle in 3D. We find that its hierarchical pseudo-orthogonal laminated microstructure exploits many extrinsic toughening mechanisms, including crack deflection, fibre and laminate pull-out and crack bridging. We highlight lessons to be learned in the design of engineering structures from the toughening methods employed.

\section{Statement of Significance}


We present the first comprehensive study of the damage and toughening mechanisms within arthropod cuticle in a 3D time-lapse manner, using X-ray nanotomography during crack growth. This technique allows lamina to be isolated despite being convex, which limits 2D analysis of microstructure. We report toughening mechanisms previously unobserved in unmineralised cuticle such as crack deflection, fibre and laminate pull-out and crack bridging; and provide insights into the effects of hierarchical microstructure on crack propagation. Ultimately the benefits of the hierarchical microstructure found here can not only be used to improve biomimetic design, but also helps us to understand the remarkable success of arthropods on Earth.

Keywords: Arthropod cuticle; Time-lapse imaging; X-ray tomography; Biological composites

\section{Introduction}

Arthropod exoskeletons typically comprise a lightweight, hierarchically organised chitin-protein composite (i.e. cuticle)[1] that can exhibit a diverse range of properties[2,3]. Many biological materials employ mineralisation to increase strength and stiffness. However, most terrestrial arthropod cuticles are not mineralised to allow rapid, energy-efficient production (thus minimising the impact of moulting) and ensuring low density, to facilitate locomotion such as flight[1,3]. An extreme case of the balance between protection and weight reduction are beetle elytra, which are unmineralised chitinous wing cases[4,5] . Indeed, they show one of the highest weight to stiffness ratios of any arthropod cuticle (Fig. 1), which makes elytra a potentially fruitful biomaterial for study. 


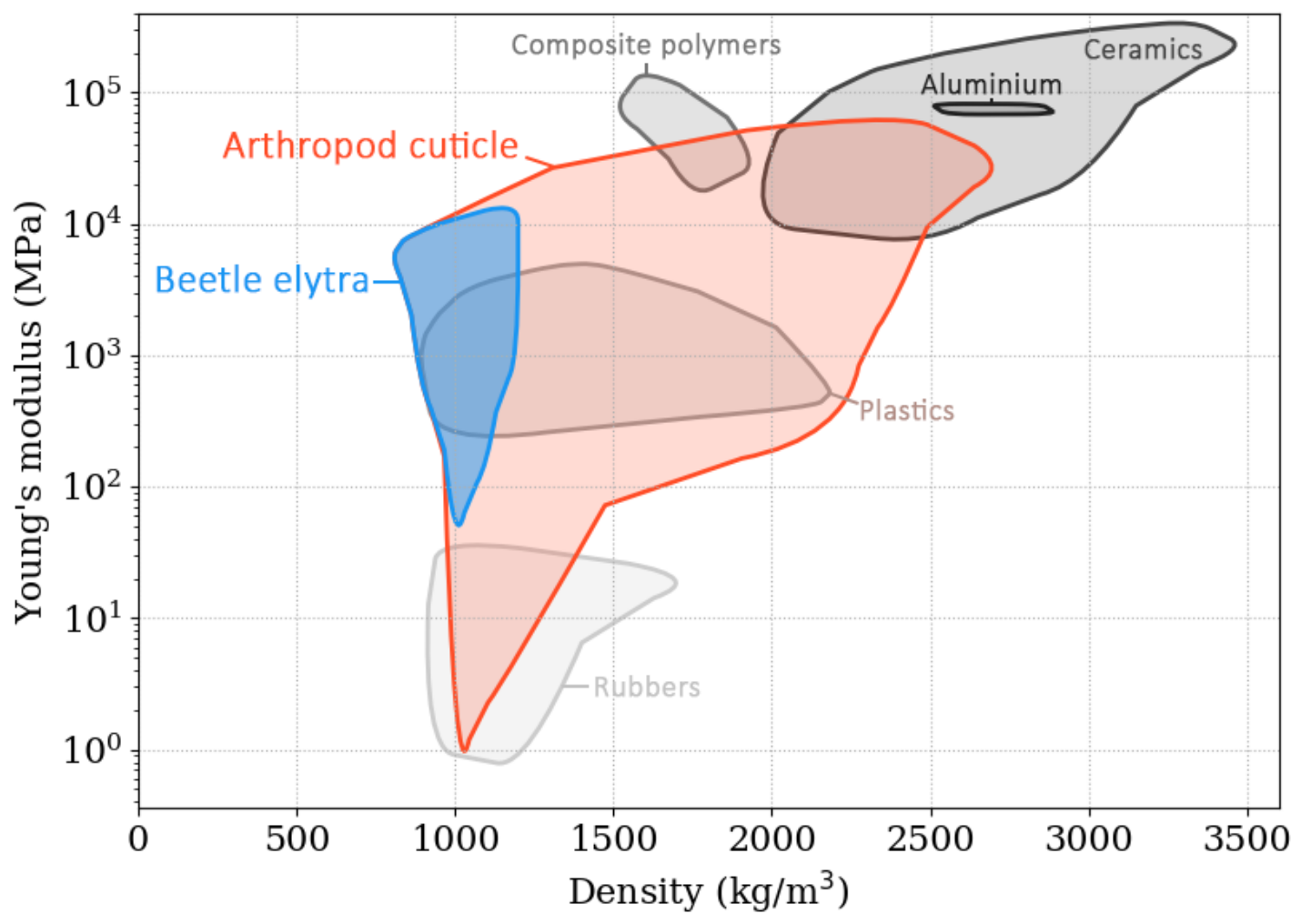

Figure 1. Ashby plot of Young's modulus against density for arthropod cuticle and a range of engineering materials[6]. Arthropod cuticle and beetle elytra data were collected from the literature (see supplementary table 1$)$.

Cuticle exhibits an extraordinary combination of high stiffness (fig. 1) and fracture toughness (the highest reported is 4.12 MPa $\mathrm{m}^{1 / 2}$ [7]) using ordinary biological constituents[3]. Like many protective biological materials[8-12], the cuticle is made up of fibres organised in laminae with orientations that rotate between successive layers. Within arthropods the following arrangements have been found: helicoid[1,4,13,14], where each unidirectional lamina of microfibres is rotated a fixed angle between successive laminae; pseudo-orthogonal or 'balken'[15], which is described in figure 2; and honeycomb and sinusoidal helicoids, which have only been found in the lobster Homarus americanus[16-18] and the mantis shrimp Odontodactylus scyllarus[19], respectively. 


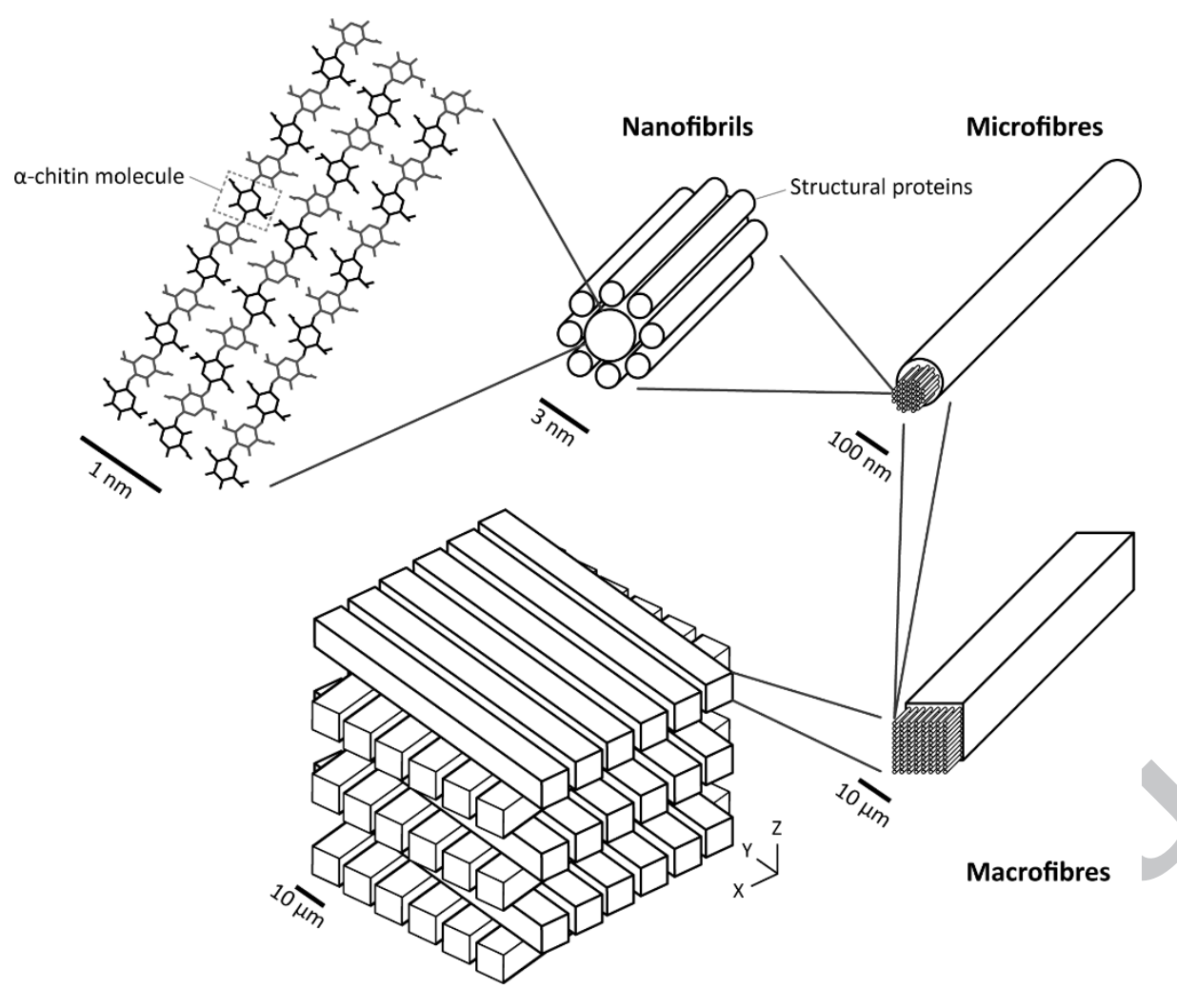

Pseudo-orthogonal structure

Figure 2. Diagram of the hierarchical, pseudo-orthogonal structure of beetle elytra cuticle. The $\alpha$-chitin molecules form long anti-parallel arrangements of $\alpha$-chitin crystalline chains. These are incorporated into bundles of chitin fibres that are bound in structural proteins to form nanofibrils. The nanofibres in turn are bundled into microfibres 100 s of nanometres in diameter, which are also bundled into macrofibres ('balken')[15] tens of micrometres wide. These form unidirectional laminae which have a pseudoorthogonal arrangement, whereby laminae rotate between alternate directions. The pseudo-orthogonal structure represented here provides a reference for the orientations in figs. 4-6. In beetles, these angles vary between $30-90^{\circ}$ with angles $\geq 60^{\circ}$ being the most common[4] and runs through the exocuticle and endocuticle layers of the cuticle[1].

Unfortunately, our current knowledge of cuticle crack propagation is relatively poor. Two types of toughening mechanism can prevent crack growth: intrinsic ones, where energy is absorbed ahead of the crack tip (e.g. plasticity in metals); and extrinsic ones, where crack growth is inhibited by shielding mechanisms absorbing energy and/or reducing the local stresses and strains at the tip (e.g. crack deflection 
in ceramics). To date fracture has been studied in two mineralised cuticles, the stone crab Menippe mercenaria[20] and $H$. americanus[21]. In the former, which has a helicoid cuticle[22], a correlation was found between lower fracture toughness and an increased pore density[20]. For dried samples of the latter, brittle fracture occurred due to agglomeration of pores, but some extrinsic toughening mechanisms were evident, i.e. crack deflection along the longitudinal edges of fibres[21]. For fresh samples, fracture occurred by stepwise crack propagation with extrinsic toughening mechanisms (delamination, crack deflection and crack bridging) implied alongside intrinsic mechanisms (plastic deformation)[21]. Fracture surfaces have been examined in the elytra of two beetles, Allomyrina dichotoma[23] and Lucanus cervus [24]: in both cases evidence of intralaminar crack bridging was found. Studies of cuticle structure have led to the development of biomimetics with improved anti-peeling properties[23,25-28], likewise studying crack propagation and structure simultaneously could lead to biomimetics with improved toughness.

Our aim is to characterise how cracks propagate through beetle elytra in the scarab beetle Macraspis lucida and to investigate the impact of its hierarchical cuticle structure, both to better understand biological design, and to inform the engineering of synthetic structures. In this paper a dry sample is studied which is less tough than fresh elytra but is more stable under prolonged X-ray examination and shows many of the same micromechanisms of toughening if with less energy absorption.

\section{Materials and methods}

\subsection{Sample preparation}

A dried ( $<1 \%$ water content) Macraspis lucida beetle specimen was donated by the Manchester Museum, University of Manchester; the elytra of this species were used as they are large, flattened and have a pseudo-orthogonal structure. The elytra were removed with tweezers and a strip of cuticle $(0.39 \pm 0.02 \mathrm{x}$ $6.4 \pm 0.32 \mathrm{~mm}$ ) was dissected using a razor blade. A scalpel was used to create a $0.076 \pm 0.004 \mathrm{~mm}$ width notch (Fig. 4a). The notched cuticle sample was then attached to aluminium tabs using epoxy glue and left 
to dry for two hours. The aluminium tabs holding the sample, were then attached to the nano-mechanical test stage[29] with epoxy glue (Fig. 4b).

\subsection{Time-lapse nano-computed tomography (nCT) with in situ crack propagation experiment}

An initial nCT scan was performed using a Zeiss Xradia 810 Ultra X-ray microscope with a chromium source. It was operated at $5.4 \mathrm{keV}$ and Zernike phase contrast was achieved using a phase ring. The sample was centred and a total of 608 equi-angularly spaced X-ray projections were taken over a $156^{\circ}$ rotation; a full $180^{\circ}$ rotation is not possible using the nano-mechanical test stage as it attenuates all the $\mathrm{X}$-rays at some projection angles. This introduces some minor cupping artefacts to the data[30]. An exposure time of 15 s/projection was used giving a total acquisition time of 2.5 hours. An in situ nano-mechanical tensile test was performed between scans: the sample was loaded until the maximum displacement of $0.5 \mathrm{~mm}$, at a strain rate of $0.01 \mathrm{~mm} / \mathrm{s}$. The gauge length of the sample was $2.87 \pm 0.14 \mathrm{~mm}$, the sample width was $0.39 \pm$ $0.02 \mathrm{~mm}$, and thickness was $0.169 \pm 0.008 \mathrm{~mm}$. Five load stages were scanned and volumetric data collected before failure occurred (Fig. 3). The sample was scanned at each loading stage using $457 \mathrm{X}$-ray projections each with an exposure time of 12 seconds, giving a total acquisition time of 1.5 hours per load stage. Due to the extended time for acquiring time-lapse tomographic sequences only one sample was studied by CT; we did however test a number of samples off-line and these showed broadly similar behaviour. 


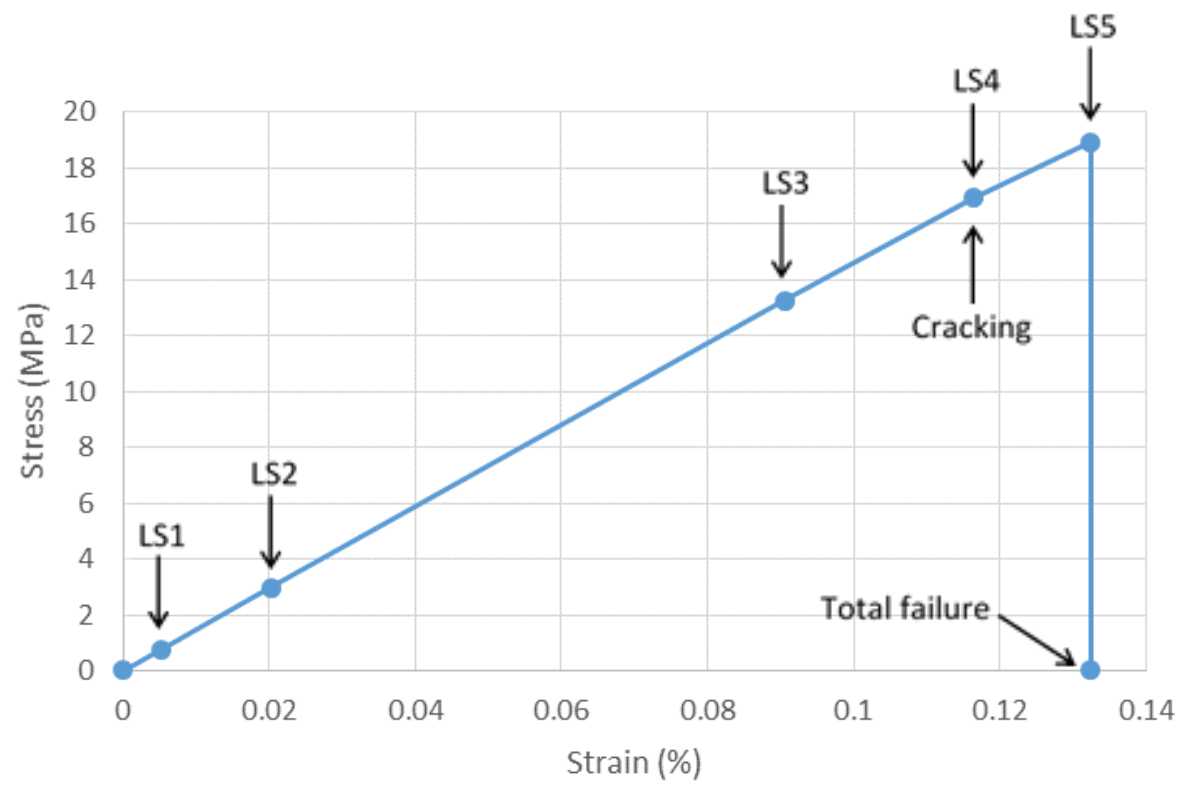

Figure 3. Stress-strain curve for in situ tensile test of dry elytra sample. Load stages (LS) 1-5 are marked to indicate where $\mathrm{nCT}$ scans were collected. Load-displacement data were collected at each load stage over a total of 53 hours, with a pause for each load stage (to allow for the displacement to settle) which took 90 minutes per $\mathrm{nCT}$ scan.

\section{3. $\mathrm{nCT}$ image reconstruction}

All volumetric data were collected with a spatial resolution of $127 \mathrm{~nm}$ and reconstructed using filtered back projection, via the TomoTools interface to the ASTRA reconstruction toolbox[31]. TomoTools is a Matlab based interface and is available from www.github/rsbradley/tomotools. Ring artefacts were reduced by applying a median filter approach to the sinograms[32], and the sinograms were padded to reduce the cupping artefacts arising from the region-of-interest scanning[30].

The grey levels of the reconstructed volumetric data were matched to that of the initial scan, taken with no load, by finding the linear transform of the data which led to the best agreement (in terms of least squared difference) between the grey level cumulative density functions. This was carried out using TomoTools and the data were exported as 3D TXM files. 


\subsection{Image analysis}

The scan data (TXM files) were imported into Avizo 9.0.0, where the laminae were visible in XZ plane views and manually segmented (Fig. 4d) every 100 slices, and then an interpolation of the segmentations was performed to isolate all the plies individually through the whole scan volume. This was performed for each load stage. The segmented plies were exported as 3D TIFF files for import into Drishti[33], where 3D visualisations of the individual plies can be made to show crack propagation through the individual plies. The angles of the fibre orientations in each lamina were measured in Avizo. All laminae were measured and the angle reported in relation to the load direction. Macrofibre and lamina sizes were also measured in Avizo.

\subsection{Statistical analysis}

All measurements were taken five times and the mean and $95 \%$ confidence intervals calculated. The fibre orientations of the laminae were measured at LS 0 and 5, then the variance for each load stage was analysed using Levene's test[34]. This analysis was performed using the SciPy package[35] in Python 3.7.

\section{Results}

\subsection{Computed nanotomography of cuticle structure}

As a non-destructive technique, computed nanotomography ( $\mathrm{nCT}$ ) allows a sequence of 3D scans to be acquired in a time-lapse manner to image damage accumulation and deformation over time and load[29]. This provides a unique perspective on the interactions between crack growth and microstructure, allowing the toughening mechanisms to be visualised during testing. For low density materials like chitin-protein fibres, X-ray attenuation is weak giving rise to low contrast. Therefore, we used Zernike phase contrast imaging[36] that generates much stronger contrast in weakly absorbing specimens [37], and highlights interfaces such as those between fibres and cracks. A $65 \mu \mathrm{m}$ region of interest, local to the notch tip of the beetle elytron sample (Fig. 4c), was imaged using nCT: sufficient to capture 10 laminae of the cuticle 


\section{ACCEPTED MANUSCRIPU}

structure (Fig. 4d). The macrofibre laminae are convex as a result of the shape of the elytron, making them difficult to visualise in orthoslices and thus the 3D datasets required segmentation (e.g. Fig. 4d). Each lamina in the cuticle is one macrofibre thick; from the $\mathrm{nCT}$ scan, the average lamina thickness is $7.37 \pm 0.15$ $\mu \mathrm{m}$, comprising macrofibres $7.37 \pm 0.16 \mu \mathrm{m}$ wide. In other words, the macrofibres have a square crosssection and form a 'balken' or pseudo-orthogonal arrangement[15]. The orientation of laminae follows an alternating pattern of $+/-30-40^{\circ}$ with respect to loading axis $\left(+/-80^{\circ}\right.$ rotation between laminae), as can be seen in table 1 . There is an increase in the rotation between more ventral laminae (8-10), which have orientations of $-63^{\circ},+4^{\circ}$ and $-106^{\circ}$ respectively, this represents a $-99^{\circ},+67^{\circ} \&-110^{\circ}$ rotation between these laminae (Table 1).

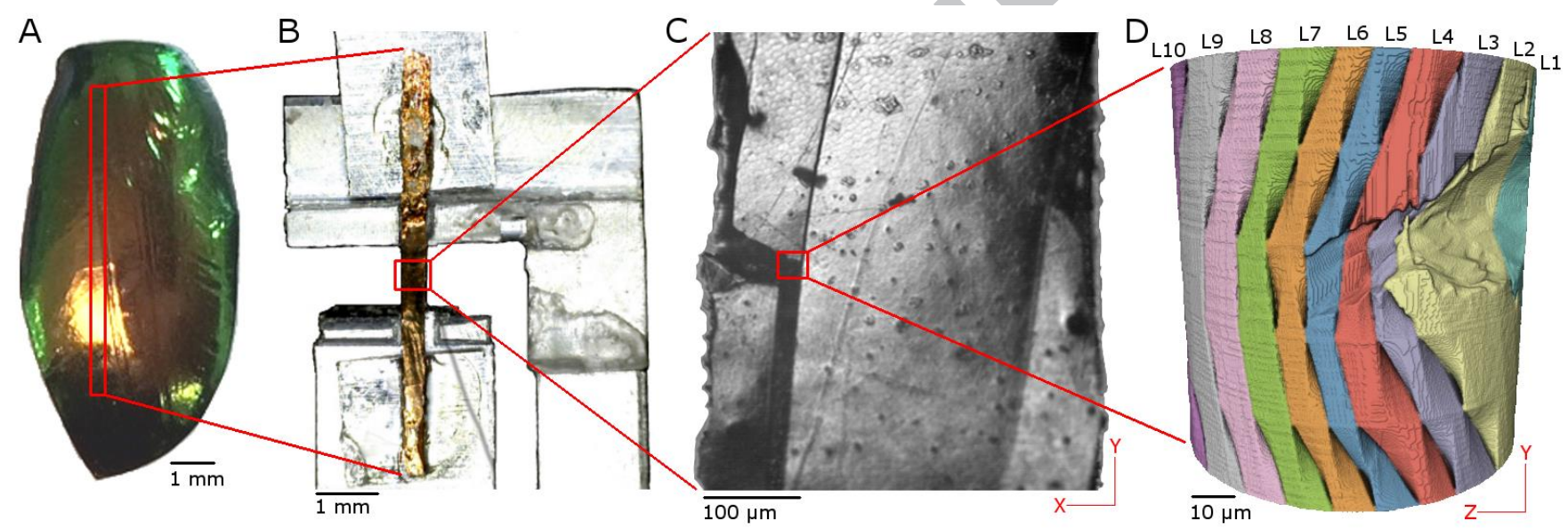

Figure 4. a, Photo of dissected M. Iucida elytron (dorsal view). b, Dissected strip of cuticle removed from elytron, notched to create a single edge notched tension (SENT) specimen, mounted in nano-mechanical testing rig. c, Optical microscope image of notched cuticle, the notch tip corresponds to $Z=0$ in the $\mathrm{nCT}$ images. d, 3D nCT image of endocuticle at notch tip segmented into laminae labelled L1-L10, L1 being the dorsal-most lamina and L10 the most ventral.

\begin{tabular}{|l|l|l|l|l|l|l|l|l|l|l|}
\hline Lamina & 1 & 2 & 3 & 4 & 5 & 6 & 7 & 8 & 9 & 10 \\
\hline Orientation & $+33^{\circ}$ & $-44^{\circ}$ & $+36^{\circ}$ & $-36^{\circ}$ & $+39^{\circ}$ & $-39^{\circ}$ & $+36^{\circ}$ & $-63^{\circ}$ & $+4^{\circ}$ & $-106^{\circ}$ \\
\hline
\end{tabular}

Table 1. Lamina orientations with respect to load direction (y axis in fig. 4), laminae numbered as shown in figure $4 d$.

\subsection{D time-lapse imaging of crack propagation in dry cuticle}


The stress-strain curve (Fig. 3) shows a linear elastic response to strain until crack initiation occurs at load stage (LS) 4. In the dry state, very little energy is dissipated before catastrophic failure occurs by brittle fracture at LS 5. Pre-existing cracks in the cuticle show no growth until LS 4. Based on our data, the modulus of toughness ( $\mathrm{U}_{\mathrm{T}}$, the area under the stress-strain curve prior to crack initiation) is 3.0 MPa. Given that the current samples are in the dry condition, our aim was not to quantify the stiffness and toughness, but rather to observe the damage sequence. Using a dry sample has the advantage that the condition of the sample (and therefore its properties) won't change during the experiment.

A time lapse sequence for the segmented central laminae $(4,5$ and 6$)$ showing the damage sequence during tensile straining for the three central laminae is shown in figure 5 , with some of the toughening mechanisms highlighted. This clearly shows that cracking initially occurs along pre-existing channels between the macrofibres and along minor damage likely introduced while handling the sample (Fig. 5 - LS 1 and 4, lamina 5). These lines of weakness open slightly $(\sim 240-280 \mathrm{~nm})$ during the initial loading stages 13. These pre-existing channels are a protein matrix that provides an interface between the chitin-protein macrofibres with covalent bonds and/or H-bonding[38]. Within a lamina the crack grows until it encounters the chitin-protein macrofibres, where it either travels along the interface between the fibres (Fig. 5 - LS 4), as the path of least resistance, or connects between interfaces by perpendicular fracturing of the macrofibres (Fig. 5 - LS 4, lamina 6). This causes the crack to be deflected away from the load direction, reducing the stress intensity and increasing the surface area of the crack, thus increasing the energy required for it to propagate.

The pseudo-orthogonal macrofibre orientations within the cuticle laminae cause the crack to develop in alternating directions in adjacent laminae. This means that energy is absorbed by sliding and pull-out between the laminae (though this sliding energy is small in the current dry case). Perpendicular macrofibre fracture also slows crack growth when the macrofibres are not aligned with the load direction. This is because the axial macrofibre stress is smaller than the applied stress, so additional local elastic stresses are required for the fibres to fracture. However, in some instances, cracks across macrofibres are deflected 
internally causing a zig-zag shear tear to occur (Fig. 5 - LS 4, lamina 4 and LS 5, lamina 5). This is likely due to the combination of lamina orientation, and the direction of principal stress or the arrangement and properties of nanofibrils and microfibres within the macrofibres. In either case it greatly increases the fracture load required to break an individual macrofibre.

As the crack grows, evidence of delaminations within the cuticle appear, for example an instance of crack bridging between macrofibres is shown in lamina 5 (Fig. 5 - LS 5). Also, fibre pull-out can be seen (Fig. 5 - LS 4, lamina 5 and LS 5, lamina 4) implying that the macrofibres and matrix have debonded to allow the crack to grow along the macrofibres. This increases the crack area perpendicular to the principal stress so that the macrofibres must be fractured and pulled out of the matrix. If the macrofibre is not broken at the same location then it will bridge the gap (Fig. 5 - LS 4, lamina 5), and requires more work to be pulled out of the matrix. Fibre pull-out is a significant toughening mechanism for composites as the elastic strain energy has to pull the fibres against friction, or shear the matrix parallel to the microfibres, while propagating the crack through the matrix[39]. Another toughening mechanism being exploited by the elytron appears to be the production of a rough-edged crack. At LS 5 this is particularly evident in lamina 5 (Fig. 5), where this roughness increases the frictional sliding force, hence shielding the crack and slowing its growth[40]. Between LS 0 and 5 the orientations of the laminae have not significantly changed at the macroscale; rotations between $-3.4^{\circ}-3.1^{\circ}$ occurred. However, the variance of measured angles within each lamina did significantly increase in LS $5\left(p=3.2 \times 10^{-6}\right.$; Levene's test), an increase in the standard deviation from $0.92^{\circ}$ in LS 0 to $3.92^{\circ}$ in LS 5. This implies that delaminations between laminae and between macrofibres are taking place in the damage zone; these rotations can also absorb energy. 


\section{ACCEPTED MANUSCRIPT}
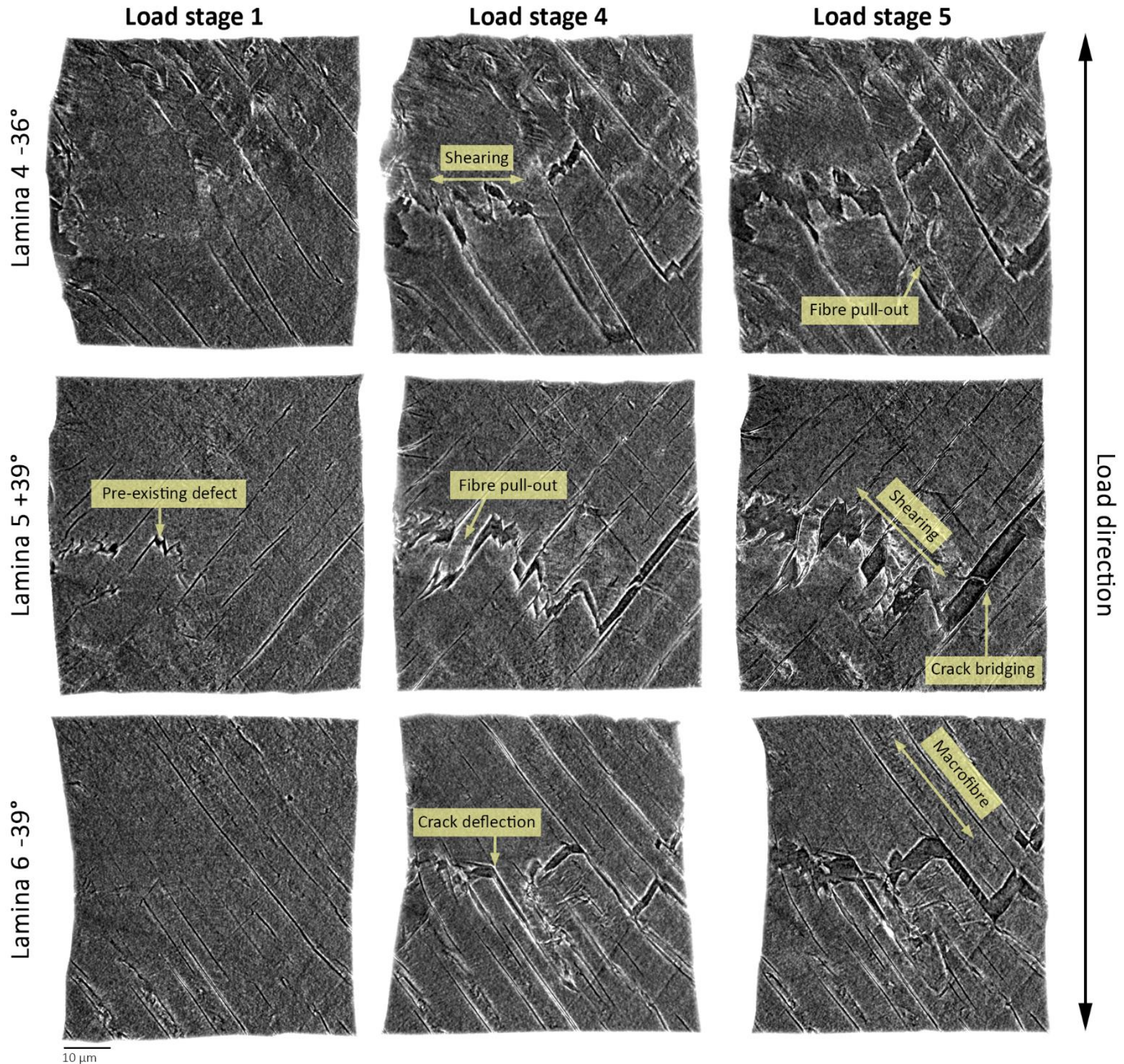

Figure 5. 3D images (thick sections in the XY plane) of the individually segmented laminae (4-6) showing crack propagation within laminae during loading.

While figure 5 predominantly shows the damage and energy absorption mechanisms within laminae, the perpendicular cross sections in figure 6 demonstrate how the damage propagates between laminae (with the tip of the notch representing $0 \mu \mathrm{m}$ ). It confirms that the crack does not have the same shape in adjacent laminae (Fig. 5 - LS 4 and Fig. 6 - LS 5, $34 \mu \mathrm{m}$ ) giving rise to pull-out between laminae. Some 
delaminations can be observed between laminae at the first loading stage (Fig. $6-$ LS 1, $10 \mu \mathrm{m}$ ) which appear to be caused by the creation of the notch, whilst some of these grow with increasing load (Fig. 6 LS5, at $10 \mu \mathrm{m}$ ) either because of higher strain in that area or due to the pre-existing damage. Deeper into the cuticle (further along the crack) delaminations are not evident (Fig. $6-19$ and $34 \mu \mathrm{m}$ ), however, since fibre pull-out is occurring in these areas, some delamination and interlaminar sliding must be occurring also.

There is evidence of further crack deflection in the YZ plane, by bifurcation of the crack (Fig. 6 - LS 4, 19 $\mu \mathrm{m}$ ) and shear tears along macrofibres (Fig. 6-LS 4, $34 \mu \mathrm{m}$ ). Bifurcations occur when the crack propagates both across and along the macrofibres simultaneously, however this is a relatively rare occurrence. The more likely outcome is that the crack is blunted by a macrofibre, forcing the crack around it and allowing the macrofibre to act as a bridge between laminae (Fig. $6-$ LS 5, at $34 \mu \mathrm{m}$ ). Both bifurcation and crack blunting act to increase the surface area of the crack and thus increase the energy required for crack growth, and both result in crack bridging which acts as an additional and important extrinsic toughening mechanism. Shear tears along macrofibres (i.e. between laminae) (Fig. 6 - LS 4, at $34 \mu \mathrm{m}$ ), increase the energy required to propagate the crack across the macrofibre. It appears that they occur due to the nature of the pseudo-orthogonal arrangement of macrofibres. As every alternate lamina has cracks travelling in the same direction, in general, it appears that shear tears cross the intermediate lamina to join these cracks. In both the $X Y$ and $Y Z$ plane the crack can be seen to follow pre-existing defects within the cuticle (Fig. 5 - LS1, lamina 5 and Fig. 6 - LS1, $19 \mu \mathrm{m}$ ). Pre-existing defects are the result of naturally occurring damage during the beetle's life and unavoidable damage due to sample preparation. In both cases, our results show the ability of beetle elytra to withstand damage. 


\section{ACCEPTED MANUSCRIPT}

Distance along $\mathrm{X}$-axis

Load stage 1

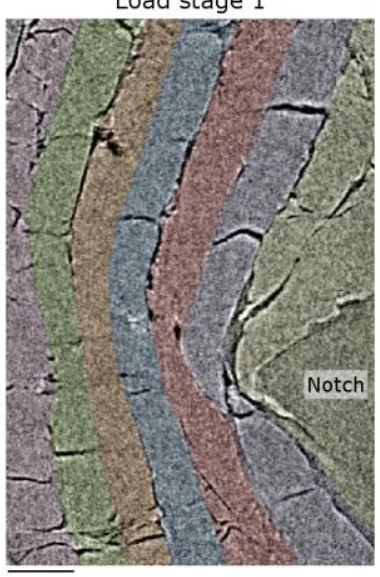

$10 \mu \mathrm{m}$
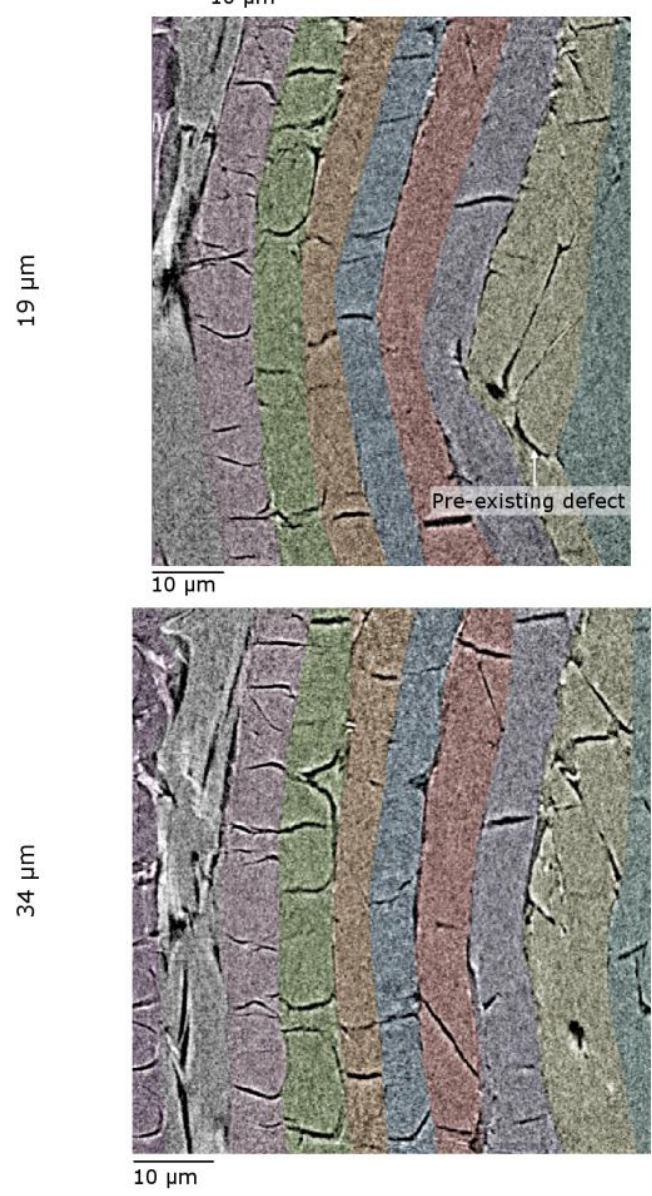

Load stage 4
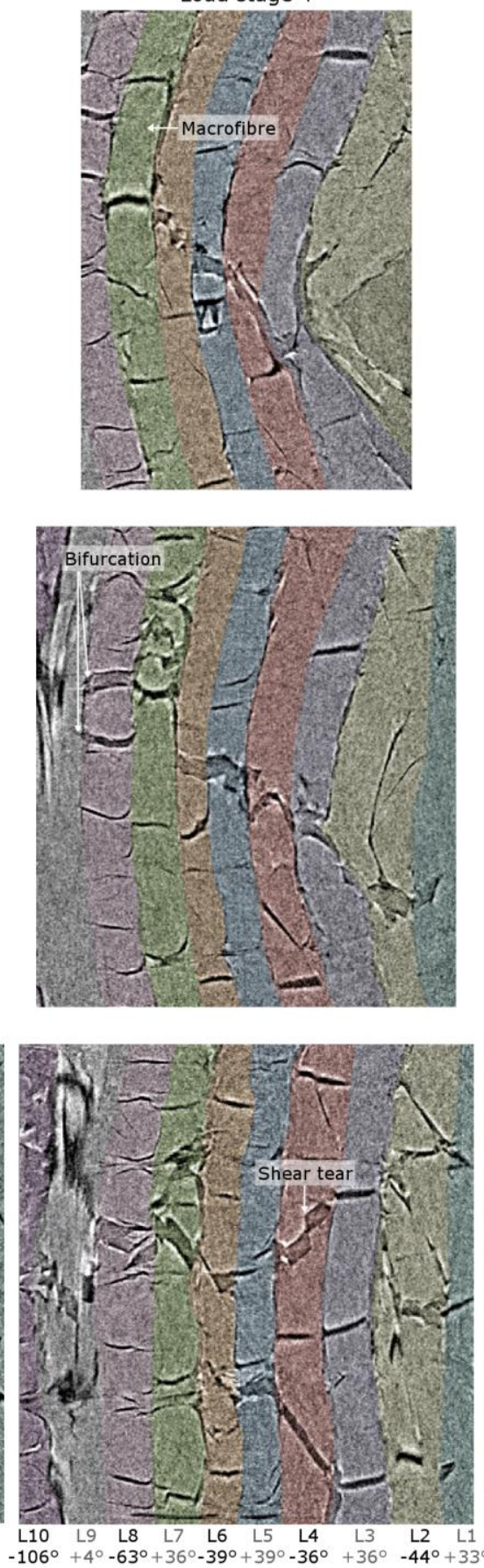

Load stage 5
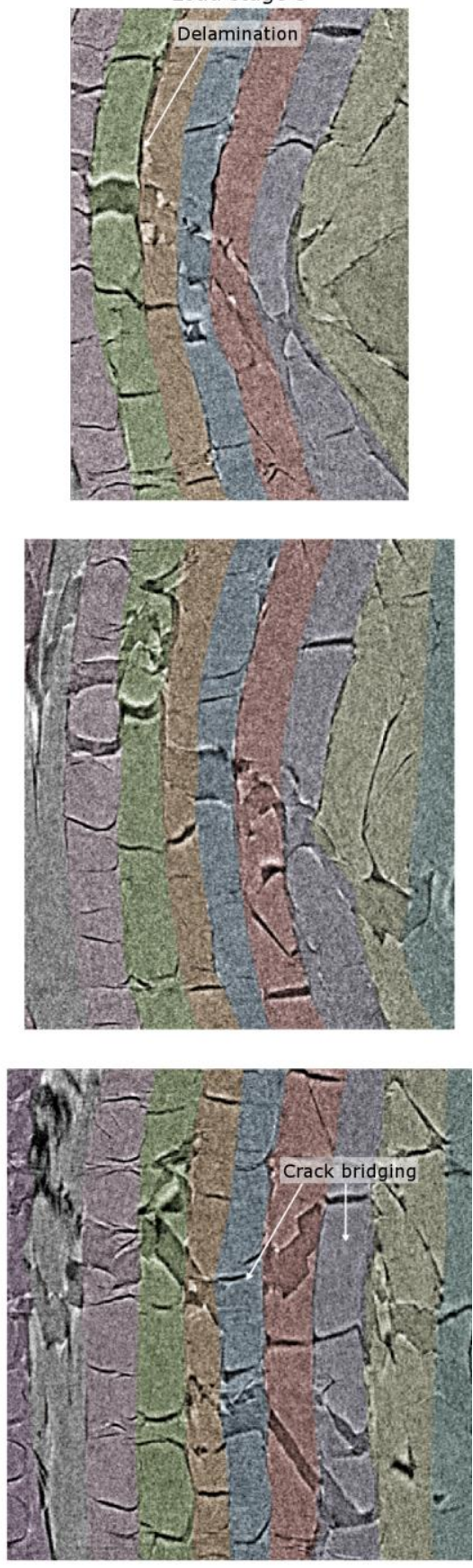

Figure 6. Virtual (YZ) CT cross sections for different distances along the X-axis (i.e. away from the notch tip), showing crack propagation along the crack length through whole scanned region from LS 1-5 with the 10 laminae segmented using different colours (L1-10). It is noteworthy that L9 has macrofibres aligned with the loading axis and L10 has macrofibres aligned perpendicular to the loading axis.

\section{Discussion}


Time-lapse nCT has provided a unique perspective: the interaction between the hierarchical structure of elytra and crack propagation, at a resolution sufficient to see interaction at the nanoscale between individual macrofibres and crack growth. This has allowed us: to observe and identify the toughening mechanisms; and to visualise the intralaminar and interlaminar damage mechanisms, within beetle elytra for the first time. The ability to segment the curved layers of macrofibres was necessary to achieve these results. This study considers only the fracture of dry beetle elytra - recently we have developed methods to preserve the cuticle in a 'fresh' state (i.e. hydration level maintained as in vivo) over a period long enough to capture a sequence of nano-tomographs (around 24-48 hours using a lab source) and work is ongoing to produce results to compare with dry cuticle. Nevertheless the current results indicate that the variety of interfaces present in cuticle across a range of scales can inhibit and frustrate crack growth.

It is clear from our results that cuticle employs many toughening mechanisms that have not previously been reported, such as crack bifurcation, shear tearing, interlaminar crack bridging, differential crack deflection between laminae and rough crack surfaces. Although cuticle utilises both intrinsic and extrinsic toughening mechanisms to slow crack growth (i.e. ahead of and behind the crack tip), dry cuticle at least appears to have little capacity for intrinsic toughening. However, dried samples are reported to have a lower fracture toughness than 'fresh' samples[7] and so more extensive toughening may be expected in the natural state. It is interesting to note that we have found more evidence of active toughening mechanisms than were present in both dry and wet lobster claw[21], however, a 3D time-lapse study of crack propagation in a mineralised cuticle such as this would likely reveal further toughening mechanisms. It will be valuable for future studies to investigate how crack propagation is affected by hydration, as fresh beetle elytron samples are likely to have a progressive and more energy-absorbing tensile failure response than dry elytra[21]. Due to the time constraints associated with carrying out a time-lapse nanoCT experiment, the results presented here are from a single sample. Nevertheless we have tested other samples offline and achieved very similar results. We believe the results are representative of the wide range of toughening mechanisms present in dry beetle elytra. In summary, the majority of toughening 
observed in this sample is extrinsic, as for ceramics. A unique aspect of toughening in cuticle, however, is that it is applied across a hierarchical structure. This simultaneously allows toughening mechanisms to occur on a number of laminae, and therefore increase their effectiveness. For example, here, crack deflection occurs in all laminae, but the deflections occur in different directions depending upon the orientation of the macrofibres within each. This greatly increases the volume of the damage zone thereby increasing the energy dissipated, and slows crack growth - more so than if the fibres had the same oblique orientation with respect to the crack direction. The hierarchical arrangement of fibres also allows delaminations and pull-out to happen along many different interfaces within the material. They can occur both within laminae (between macrofibres and surrounding matrix) or between laminae; this increases the energy dissipated and spreads the damage away from the principal stress direction. We also report unexpected variations in the pseudo-orthogonal laminate lay-up structure. In contrast to the regular $\pm 80^{\circ}$ misorientation between successive lamina observed for laminates 1-8, a quite different misorientation was observed for lamina 9 and 10 (those nearest to the interior). We speculate that these laminae may act to contain damage within different zones of the cuticle by preventing cracks spreading from the outer surface to deeper lamina within the cuticle. The crack path and toughening mechanisms found visually, imply a brittle-ductile laminate structure, however the stress-strain curve does not reflect this and appears to imply a brittle structure. Ex situ loading and unloading tests of elytra found some evidence of stress relaxation and plastic deformation in their stress-strain curves, however it may be that in dried samples the interfaces are too weak to absorb much energy, resulting in a brittle fracture. These interfaces need to be reasonably weak to provide the best combination of properties in the composite material, however it would be expected that in a hydrated sample the interfaces would be more elastic $[7,41]$ therefore increasing both the energy they absorb and that is required for delaminations to occur. This would result in a more ductile fracture and a higher fracture toughness in the cuticle[3,21].

\section{Conclusions}


This study found that dry M. lucida elytra has a high modulus of toughness relative to most other

arthropod cuticles. This implies that these beetle elytra are adapted to tolerate high impact loads[3], and they also have high punch strength[42]. These properties are advantageous for protecting the delicate wings underneath the elytra from both accidental damage and predators. However, this is for a dried elytron, cuticle has been found to be tougher when more hydrated[3]. For meaningful comparisons of fracture properties in relation to cuticle structure, composition and condition, more cuticles need to be measured, ideally in a fresh state. Nevertheless, this study highlights the effectiveness of a hierarchical laminated structure for producing tough materials even when the biomaterial itself is produced from simple constituents. These hierarchical structures are used in many protective biomaterials like fish scales[8,9], mollusc shells[10,11], and plant cuticle[12]. This implies a general benefit for toughness in using hierarchical organisation, and in the case of arthropod cuticle, we have found many complimentary toughening mechanisms across this structure. It seems that arthropods benefit from an ability to produce tough cuticle for defence quickly and at low energetic cost, as it can be assembled at room temperature in less than 24 hours[1]. Cuticle has one of the highest reported fracture toughnesses of any biomaterial[7] and yet until now the full range of crack shielding mechanisms and their interactions during crack propagation had not been captured. Our study has found that misorientations between laminae of unidirectional fibres has a large impact on the direction of crack growth and could be a useful design to apply to the production of tougher carbon-fibre composites. We speculate that one potential benefit of a pseudo-orthogonal structure over an orthogonal arrangement is that the differently orientated lamina (L810) could shield deeper layers from surface damage. We found that many extrinsic toughening mechanisms are used by cuticle, which are intimately linked to its structural organisation, however a largely brittle fracture still occurred. It is likely that this is due to dehydration causing the interfaces between fibres at every scale of the hierarchical structure to become weaker. Further study of the effect that different microstructures, compositions and conditions of cuticle have upon its toughening mechanisms could provide many lessons in biomimetic design of new materials. Another important reason 
for understanding why arthropods use different cuticle microstructures and how these are advantageous,

is that it could aid our understanding of why arthropods are the most successful group of animals on Earth.

\section{References}

[1] A.C. Neville, Biology of the arthropod cuticle, Springer-Verlag, 1975.

[2] M.F. Ashby, L.J. Gibson, U. Wegst, R. Olive, The Mechanical Properties of Natural Materials. I. Material Property Charts, Proc. R. Soc. Math. Phys. Eng. Sci. 450 (1995) 123-140. doi:10.1098/rspa.1995.0075.

[3] J.F.V. Vincent, U.G.K. Wegst, Design and mechanical properties of insect cuticle, Arthropod Struct. Dev. 33 (2004) 187-199. doi:10.1016/j.asd.2004.05.006.

[4] T. van de Kamp, A. Riedel, H. Greven, Micromorphology of the elytral cuticle of beetles, with an emphasis on weevils (Coleoptera: Curculionoidea), Arthropod Struct. Dev. 45 (2016) 14-22. doi:10.1016/j.asd.2015.10.002.

[5] Z. Dai, Z. Yang, Macro-/Micro-Structures of Elytra, Mechanical Properties of the Biomaterial and the Coupling Strength Between Elytra in Beetles, J. Bionic Eng. 7 (2010) 6-12. doi:10.1016/S16726529(09)60187-6.

[6] M. Ashby, D. Cebon, Materials selection in mechanical design, J. Phys. IV Colloq. 3 (1993) 1-9. doi:10.1051/jp4:1993701.

[7] J.-H. Dirks, D. Taylor, Fracture toughness of locust cuticle, J. Exp. Biol. 215 (2012) 1502-1508. doi:10.1242/jeb.068221.

[8] A. Bigi, M. Burghammer, R. Falconi, M.H.J. Koch, S. Panzavolta, C. Riekel, Twisted Plywood Pattern of Collagen Fibrils in Teleost Scales: An X-ray Diffraction Investigation, J. Struct. Biol. 136 (2001) 137-143. doi:10.1006/jsbi.2001.4426.

[9] M.M. Giraud, J. Castanet, F.J. Meunier, Y. Bouligand, The fibrous structure of coelacanth scales: A twisted 'Plywood,' Tissue Cell. 10 (1978) 671-686. doi:10.1016/0040-8166(78)90054-X.

[10] S. Kamat, X. Su, R. Ballarini, A.H. Heuer, Structural basis for the fracture toughness of the shell of the conch Strombus gigas, Nature. 405 (2000) 1036-1040. doi:10.1038/35016535.

[11] A.P. Jackson, J.F.V. Vincent, R.M. Turner, The Mechanical Design of Nacre, Proc. R. Soc. Lond. B Biol. Sci. 234 (1988) 415. doi:10.1098/rspb.1988.0056.

[12] D. Reis, B. Vian, J.-C. Roland, Cellulose-glucuronoxylans and plant cell wallstructure, Micron. 25 (1994) 171-187. doi:10.1016/0968-4328(94)90041-8.

[13] Y. Bouligand, Twisted fibrous arrangements in biological materials and cholesteric mesophases, Tissue Cell. 4 (1972) 189-217. doi:10.1016/S0040-8166(72)80042-9.

[14] H.-O. Fabritius, A. Ziegler, M. Friák, S. Nikolov, J. Huber, B.H.M. Seidl, S. Ruangchai, F.I. Alagboso, S. Karsten, J. Lu, A.M. Janus, M. Petrov, Li-Fang Zhu, P. Hemzalová, S. Hild, D. Raabe, J.

Neugebauer, Functional adaptation of crustacean exoskeletal elements through structural and compositional diversity: a combined experimental and theoretical study, Bioinspir. Biomim. 11 (2016) 055006. doi:10.1088/1748-3190/11/5/055006.

[15] T. van de Kamp, H. Greven, On the Architecture of Beetle Elytra, Entomol. Heute. 22 (2010) 191-204.

[16] D. Raabe, P. Romano, C. Sachs, A. Al-Sawalmih, H.-G. Brokmeier, S.-B. Yi, G. Servos, H.G. Hartwig, Discovery of a honeycomb structure in the twisted plywood patterns of fibrous biological nanocomposite tissue, J. Cryst. Growth. 283 (2005) 1-7. doi:10.1016/j.jcrysgro.2005.05.077.

[17] P. Romano, H. Fabritius, D. Raabe, The exoskeleton of the lobster Homarus americanus as an example of a smart anisotropic biological material, Acta Biomater. 3 (2007) 301-309. doi:10.1016/j.actbio.2006.10.003.

[18] H.-O. Fabritius, C. Sachs, P.R. Triguero, D. Raabe, Influence of Structural Principles on the Mechanics of a Biological Fiber-Based Composite Material with Hierarchical Organization: The Exoskeleton of the Lobster Homarus americanus, Adv. Mater. 21 (2009) 391-400. doi:10.1002/adma.200801219. 
[19] N.A. Yaraghi, N. Guarín-Zapata, L.K. Grunenfelder, E. Hintsala, S. Bhowmick, J.M. Hiller, M. Betts, E.L. Principe, J.-Y. Jung, L. Sheppard, R. Wuhrer, J. McKittrick, P.D. Zavattieri, D. Kisailus, A Sinusoidally Architected Helicoidal Biocomposite, Adv. Mater. (2016) 1-10. doi:10.1002/adma.201600786.

[20] C.A. Melnick, Z. Chen, J.J. Mecholsky, Hardness and toughness of exoskeleton material in the stone crab, Menippe mercenaria, J. Mater. Res. 11 (1996) 2903-2907. doi:10.1557/JMR.1996.0367.

[21] C. Sachs, H. Fabritius, D. Raabe, Experimental investigation of the elastic-plastic deformation of mineralized lobster cuticle by digital image correlation, J. Struct. Biol. 155 (2006) 409-425. doi:10.1016/j.jsb.2006.06.004.

[22] G.F. Warner, The biology of crabs, Elek, 1977.

[23] J.X. Chen, M. Iwamoto, Q.Q. Ni, K. Kurashiki, K. Saito, Laminated Structure and Its Mechanical Properties of the Fore-Wing of Beetle, J. Soc. Mater. Sci. Jpn. 50 (2001) 455-460.

[24] L. Kundanati, S. Signetti, H.S. Gupta, M. Menegon, N.M. Pugno, Multilayer stag beetle elytra perform better under external loading via non-symmetric bending properties, J. R. Soc. Interface. 15 (2018) 113. doi:10.1098/rsif.2018.0427.

[25] J.X. Chen, Q. Zu, G. Wu, J. Xie, W. Tuo, Review of beetle forewing structures and their biomimetic applications in China: (II) On the three-dimensional structure, modeling and imitation, Mater. Sci. Eng. C. 55 (2015) 620-633. doi:10.1016/j.msec.2015.04.045.

[26] J.X. Chen, Biomimetic research on beetle forewings in twenty years: Internal structure, model and integrated honeycomb plates, Sci. Sin. Technol. 48 (2018) 701-718.

[27] B. Chen, X. Peng, J. Fan, Fiber-reinforced characteristics of chafer cuticle and research on structure of branched fiber, Chin. J. Mater. Res. 17 (2003) 630-636.

[28] J.X. Chen, Q.Q. Ni, J. Xie, The Lightweight Composite Structure and Mechanical Properties of the Beetle Forewing, in: N. Hu (Ed.), Compos. Their Prop., InTech, 2012. doi:10.5772/48807.

[29] B.M. Patterson, N.L. Cordes, K. Henderson, J.C.E. Mertens, A.J. Clarke, B. Hornberger, A. Merkle, S. Etchin, A. Tkachuk, M. Leibowitz, D. Trapp, W. Qiu, B. Zhang, H. Bale, X. Lu, R. Hartwell, P.J. Withers, R.S. Bradley, In Situ Laboratory-Based Transmission X-Ray Microscopy and Tomography of Material Deformation at the Nanoscale, Exp. Mech. (2016). doi:10.1007/s11340-016-0197-3.

[30] A. Kyrieleis, V. Titarenko, M. Ibison, T. Connolley, P.J. Withers, Region-of-interest tomography using filtered backprojection: assessing the practical limits, J. Microsc. 241 (2011) 69-82. doi:10.1111/j.1365-2818.2010.03408.x.

[31] W. van Aarle, W.J. Palenstijn, J. De Beenhouwer, T. Altantzis, S. Bals, K.J. Batenburg, J. Sijbers, The ASTRA Toolbox: A platform for advanced algorithm development in electron tomography, Ultramicroscopy. 157 (2015) 35-47. doi:10.1016/j.ultramic.2015.05.002.

[32] R.A. Ketcham, New algorithms for ring artifact removal, in: U. Bonse (Ed.), Proc. SPIE, 2006: pp. 17. doi:10.1117/12.680939.

[33] A. Limaye, Drishti: a volume exploration and presentation tool, in: S.R. Stock (Ed.), 2012: p. 85060X. doi:10.1117/12.935640.

[34] H. Levene, Robust tests for equality of variances, in: Contrib. Probab. Stat. Essays Honor Harold Hotell., Stanford University Press, 1960: pp. 278-292.

[35] E. Jones, T. Oliphant, P. Peterson, SciPy: open source scientific tools for Python, 2001. http://www.scipy.org/.

[36] P.J. Withers, X-ray nanotomography, Mater. Today. 10 (2007) 26-34.

[37] R.S. Bradley, P.J. Withers, Correlative multiscale tomography of biological materials, MRS Bull. 41 (2016) 549-556. doi:10.1557/mrs.2016.137.

[38] J.F.V. Vincent, Arthropod cuticle: a natural composite shell system, Compos. Part Appl. Sci. Manuf. 33 (2002) 1311-1315.

[39] A. Kelly, Strong solids, 2nd edn. Clarendon, Oxford, 1973.

[40] R. Ballarini, M.E. Plesha, The effects of crack surface friction and roughness on crack tip stress fields, Int. J. Fract. 34 (1987) 195-207. doi:10.1007/BF00019717.

[41] D. Klocke, H. Schmitz, Water as a major modulator of the mechanical properties of insect cuticle, Acta Biomater. 7 (2011) 2935-2942. doi:10.1016/j.actbio.2011.04.004. 
[42] A.R. Evans, G.D. Sanson, Biomechanical properties of insects in relation to insectivory: cuticle thickness as an indicator of insect "hardness" and "intractability," Aust. J. Zool. 53 (2005) 9. doi:10.1071/ZO04018. 
Acknowledgements

We would like to thank Richard Preziosi and the Manchester Museum for guidance and donation of beetles for this study. We are very grateful for the helpful comments of the anonymous reviewers. Also we would like to acknowledge the assistance of the Manchester X-ray Imaging Facility, which was funded in part by the EPSRC (grants EP/F007906/1, EP/F001452/1 and EP/I02249X/1).

Author contributions

P.J.W. and R.H. conceived the study. R.H. and R.S.B. planned and performed the nCT experiment. R.S.B. reconstructed the nCT data. D.S. analysed the data, interpreted the results and wrote the manuscript. All the authors discussed the results and commented on the manuscript. 


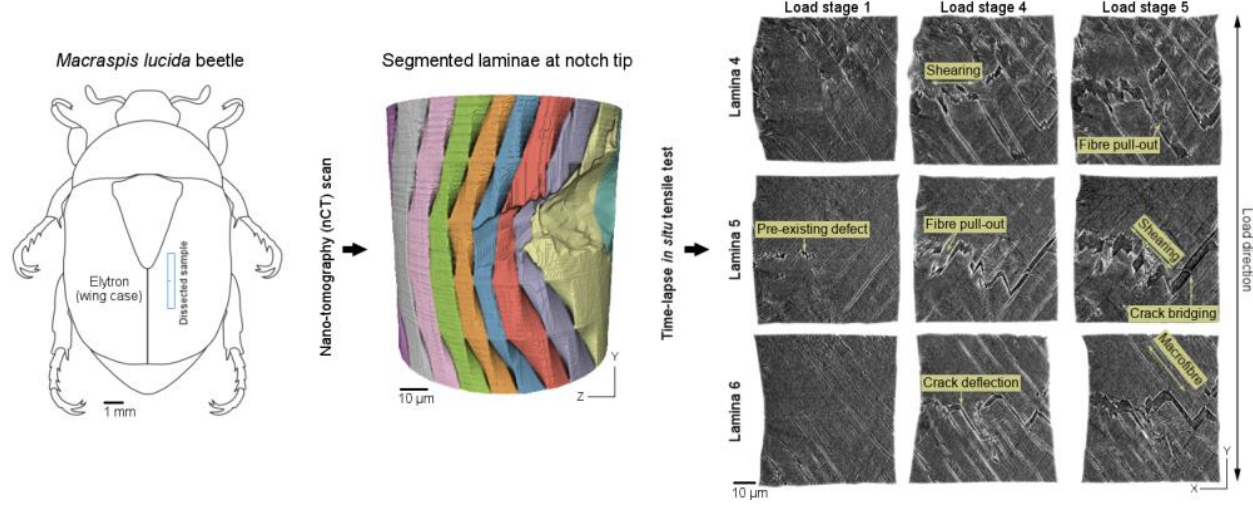

